\title{
Phenotypic, functional, and quantitative characterization of canine peripheral blood monocyte-derived macrophages
}

\author{
R Bueno, MN Mello*, CAS Menezes**, WO Dutra**, RL Santos/ ${ }^{+}$
}

Departamento de Clínica e Cirurgia Veterinárias, Escola de Veterinária *Departamento de Parasitologia **Departamento de Morfologia, ICB, Universidade Federal de Minas Gerais, Av. Antônio Carlos 6627, 31270-901 Belo Horizonte, MG, Brasil

The yield as well as phenotypic and functional parameters of canine peripheral blood monocyte-derived macrophages were analyzed. The cells that remained adherent to Teflon after 10 days of culture had high phagocytic activity when inoculated with Leishmania chagasi. Flow cytometric analysis demonstrated that more than $80 \%$ of cultured cells were positive for the monocyte/macrophage marker CD14.

Key words: monocyte-derived macrophage - canine - flow-cytometry

Macrophages play an important role in defense against infection, particularly those caused by intracellular pathogens. In addition, they are involved in phagocytic removal of cells and cell debris, and play a key role in both innate and adaptative immune response. These cells exhibit functional, morphological, and metabolic diversity depending on tissue environment as well as their stage of differentiation or activation (Janeway et al. 2001). The immune response against Leishmania is highly dependent upon macrophages, and although they are the host cells targeted for infection, they are capable of antigen-presentation and killing intracellular Leishmania (Pinelli et al. 1999). Importantly, mature macrophages from animal tissues are not readily available for culture and functional analysis. Therefore the use of monocytes-derived macrophages for functional studies is a very attractive alternative (Saldarriaga 2003), particularly because it requires a less invasive approach for obtaining the cells when compared to peritoneal or bone marrow-derived macrophages. Such a notion is important considering the animal welfare issues that are currently becoming more significant when designing experiments in which companion animals are studied. Isolation, culture, and characterization of alveolar and peritoneal macrophages (Shaw \& Anderson 1984), bone marrow-derived macrophages (Tipold et al. 1998), and canine macrophage cell lines derived from malignant histiocytosis (Pinelli et al. 2000) have been described. However, as pointed out above, the procedures for obtaining these cells are not simple and less convenient than obtaing cells from blood, although the amount of monocytes that can be isolated from blood is usually relatively low (Ho \& Babiuk 1979).

Unlike monocyte-derived macrophages from other animal species such as porcine, caprine (Wardley et al.

Financial support: Waltham Foundation, Leicestershire, UK + Corresponding author. E-mail: rsantos@ vet.ufmg.br

Received 11 May 2005

Accepted 1st August 2005
1980), ovine (Olivier et al. 2001), and bovine (Saldarriaga et al. 2003), canine monocyte-derived macrophages have not been examined in detail in spite of its previous use in research (Kurzman et al. 1993, Panaro et al. 1998, Sisto et al. 2001).

Considering the lack of information about the characterization of canine monocyte-derived macrophages as well as a standardized procedure for isolation, culture, and infection of these cells with Leishmania, we performed a quantitative and qualitative analysis of monocyte-derived macrophages isolated from canine peripheral blood. In addition, these cells were inoculated with $L$. chagasi promastigotes to assess their phagocytic activity.

Peripheral blood was collected from 22 adult healthy dogs of both genders by jugular punction into heparanized tubes. The blood was processed for blood analysis and for isolation of peripheral blood mononuclear cells (PBMC). Blood $(60 \mathrm{ml})$ was centrifuged at $1600 \mathrm{~g}$ for 10 min at room temperature, plasma was separated, blood cells were ressuspended in phosphate buffered saline (PBS) (1:1 proportion), overlaid onto a Ficoll solution (Ficoll-paque Plus, Amershan Biosciences, Little Chalfont, UK) (at 1 Ficoll: 2 blood proportion), and then centrifuged at $1200 \mathrm{~g}$ for $40 \mathrm{~min}$ at $18^{\circ} \mathrm{C}$. PBMC were separated, washed twice on PBS, and ressuspended in $8 \mathrm{ml}$ of RPMI-1640 (Gibco, Carlsbad, US) supplemented with $10 \%$ fetal bovine serum, L-glutamine $(200 \mathrm{mM})$, pyruvate $(10 \mathrm{mM})$, non essential aminoacids (10 mM), sodium bicarbonate solution (7.5\% w/v) (Gibco, Carlsbad, US), penicilin (50 IU/ $\mathrm{ml})$, and streptomicin $(50 \mu \mathrm{l} / 100 \mathrm{ml})$. The cell suspension was then transferred to Teflon flasks (NalgeNunc, Rochester, US), and cultured at $37^{\circ} \mathrm{C}$ with $5 \% \mathrm{CO}_{2}$ (Forma Scientific Incubator, Waltham, US). The medium was changed to remove non-adherent cells $24 \mathrm{~h}$ later, and the culture was kept under the same conditions for 10 days, changing the medium every 3 days. Ten days is the time required for differentiation of monocytes into macrophages (Wardley et al. 1980). Therefore, after 10 days of culture, the cells formed a confluent monolayer, mainly as a result of cell spreading as observed by phase microscopy. At this point, the macrophage-containing Teflon flasks were 
placed onto ice for $30 \mathrm{~min}$ followed by agitation for harvesting the cells, which were centrifuged at $2000 \mathrm{~g}$ for 10 min, and ressuspend in RPMI-1640. Cell viability was assessed by trypan blue staining, the concentration of the cell suspension was adjusted to 300,000 viable cells $/ \mathrm{ml}$, and the cells were seeded onto a chamber slide (Lab-Tek, NalgeNunc, Rochester, US). In order to analyze the phagocytic activity of these cells, they were inoculated with L.(Leishamania) chagasi promastigotes (international code MCAN/BR/2002/BH400) with a multiplicity of infection (MOI) of 10 in duplicates. This strain was isolated from a spleen of a naturally infected dog from the urban area of Belo Horizonte, Minas Gerais, Brazil, and cultured in $\alpha$-MEM medium, $\mathrm{pH} 7.4$, supplemented with $10 \%$ fetal bovine serum and penicilin $(50 \mathrm{IU} / \mathrm{ml})$ at $24^{\circ} \mathrm{C}$ (B.O.D. Fanem Incubator, São Paulo, Brazil). Twenty-four or $72 \mathrm{~h}$ after infection, the cells were stained with a modified Giemsa stainig system (Diff-Quick Laborclin, Pinhais, Brazil), and the infection rate established by counting 200 cells from each chamber (two chambers per dog). In addition to the blood sample for PBMC isolation, an aliquot of $5 \mathrm{ml}$ of total peripheral blood was obtained at the same time for blood cells counting.

In order to further characterize the monocyte-derived macrophages, CD14 expression was assessed in PBMC from 9 healthy adult dogs of both genders. CD14 expression was evaluated in PBMC soon after separation in a Ficoll gradient as described above or after 10 days in culture in Teflon Flasks. The cells were washed two times in PBS, and $2 \times 10^{5}$ cells were incubated with a monoclonal antibody anti-CD14 (anti-M-M9:VMRD, Pullman, US) in 96-well-U-bottom microtiter plates for $15 \mathrm{~min}$ at room temperature and then washed with PBS with $0.1 \%$ BSA and $0.01 \%$ sodium azida, followed by centrifugation for $10 \mathrm{~min}$ at $128 \mathrm{~g}$. The samples were then incubated with a secondary goat anti-mouse IgG labeled with fluorescein isothiocyanate (FITC) (Sta. Cruz Biotechnol., Santa Cruz, US). The cells were then fixed with $2 \%$ formaldehyde, and analyzed on a FACScan (Becton-Dickinson, San Jose, US). A minimum of 20,000 cells were acquired from each sample. After gating on the monocyte/macrophage region according to size and granularity profiles, the percentage of $\mathrm{CD} 14^{+}$cells was determined, as previously described (Souza et al. 2004).

The parameters were submitted to the KolmogorovSmirnov Normality Test, and means were compared by the Wilcoxon Signed Ranks Test. Pearson correlation's test was applied to the values of blood monocytes and PBMC or Teflon-adherent cells. The statistical analysis was performed using the software SPSS 11.0 (Siqueira 2002).

A functional analysis of the monocyte-derived macrophages was performed by evaluating their phagocytic activity. Inoculation with $L$. chagasi was employed here since this method of macrophage isolation and culture will be used for future studies of Leishmania-host interaction in our laboratory. The percentages of macrophage containing amastigotes (Fig. 1) at 24 and $72 \mathrm{~h}$ post inoculation were $75.93 \pm 9.81 \%$ and $76.70 \pm 14.65 \%$, respectively $(\mathrm{n}=22 \mathrm{dogs}$, 200 cells counted per dog, in duplicates). No statistically significant difference was observed between these two time points $(\mathrm{P}>0.05)$. These percentages of infection are similar to the previously reported for monocyte-derived macrophages (Panaro et al. 1998), peritoneal and alveolar (Shaw \& Anderson 1984), or bone marrow-derived macrophages (Tipold et al. 1998), indicating a phagocytic activity compatible with that of macrophages obtained by more invasive methods.

As depicted in the Table, the number of monocytes in canine peripheral blood is highly variable (Dienzle 2002). Therefore, it is reasonable to hypothesize that the yield of macrophages in culture would be directly proportional to the number of monocytes in the blood used for PBMC isolation. Interestingly, we found a non significant low

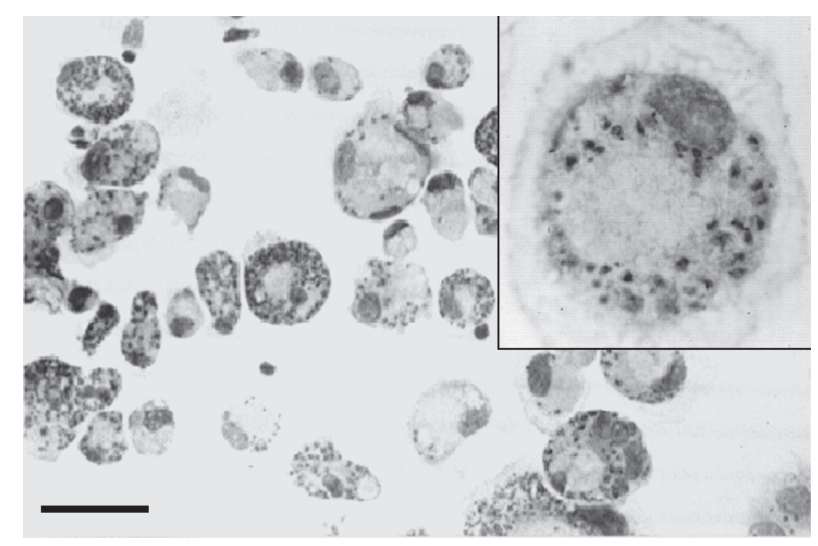

Fig. 1: canine monocyte-derived macrophages at $24 \mathrm{~h}$ post inoculation with Leishmania chagasi with variable number of intracellular amastigotes. Inset: detail of a moderately infected macrophage. Modified Giemsa staining. Bar $=50 \mu \mathrm{m}$.

\section{TABLE}

Correlation analysis between monocyte counts in the blood of $22 \mathrm{dogs}$, and the number of peripheral blod mononuclear cells (PBMC) obtained by separation through a Ficoll gradient or the number of Teflon-adherent cells (macrophages) after 10 days of culture

\begin{tabular}{ccr}
\hline $\begin{array}{c}\text { Monocytes/ml of total blood } \\
3.4 \times 10^{8} \pm 2.5 \times 10^{8}\end{array}$ & Teflon-adherent cells ${ }^{a}$ & Correlation \\
\hline PBMC $^{b}$ & $4.1 \times 10^{5} \pm 1.3 \times 10^{5}$ & $\mathrm{r}=-0.35(\mathrm{P}=0.114)$ \\
$3.7 \times 10^{7} \pm 2.3 \times 10^{7}$ & Teflon-adherent cells ${ }^{a}$ & Correlation \\
\hline : & $4.1 \times 10^{5} \pm 1.3 \times 10^{5}$ & $\mathrm{r}=0.36(\mathrm{P}=0.334)$
\end{tabular}

$a$ : total number of Teflon-adherent cells harvested after 10 days of culture; $b$ : total number of PBMC obtained from $60 \mathrm{ml}$ of total blood immediately after separation in a Ficoll gradient. 
and negative correlation between the number of monocyte-derived macrophages after 10 days in culture and the number of monocytes in the blood sample that originated the culture (Table). This result indicates that the number of monocytes in a given blood sample is not predictive at all of the macrophage yield. In contrast, the amount of blood leukocytes obtained after separation in a Ficoll gradient correlated positively but not significantly with the number of macrophages harvested after 10 days of culture (Table). Importantly, only 1.5 to $5 \%$ of original number of PBMC transferred into the Teflon flasks remained adherent by 10 days of culture.

To ensure that the population of adherent cells after 10 days of culture were indeed enriched for a macrophage phenotype, expression of the monocyte/macrophage marker CD14 (Janeway et al. 2001) was assessed by flow cytometry. The percentages of $\mathrm{CD} 14^{+}$cells, were $39.11 \pm$ $16.19 \%$ and $84.17 \pm 7.40 \%$ (mean \pm standard deviation) in the population of PBMC immediately after separation in a Ficoll gradient and Teflon adherent cells after 10 days of culture, respectively (Fig. 2). These percentages were significantly different $(\mathrm{P}=0.008)$. These results clearly indicate that culture in Teflon flasks resulted in a strong se- lection for $\mathrm{CD} 14^{+}$cells, which is supposedly achieved by the removal of non-adherent PBMC such as lymphocytes, wich are CD14-. Saldarriaga et al. (2003) found similar results with bovine peripheral blood monocyte-derived macrophages monolayer after 11 days of culture, when 94\% of cultured cells were CD14 ${ }^{+}$.

Fig. 2 also indicates an increase in size (x axis) and granularity (y axis) of Teflon-adherent cells after 10 days in culture. This finding is in good agreement with the fact that the culture was enriched for macrophages, which are larger and more granular than PBMC such as monocytes and lymphocytes (Dienzler 2002).

Taken together our data demonstrate that canine peripheral blood monocyte-derived macrophages are phenotipically and functionally suitable for biological experimentation, which might make this approach the first choice when animal welfare issues are a relevant aspect for the experimental design.

\section{ACKNOWLEDGEMENTS}

To Soraia de Oliveira for technical support. RB is supported by the Pontificia Universidade Católica de Minas Gerais, Brazil.
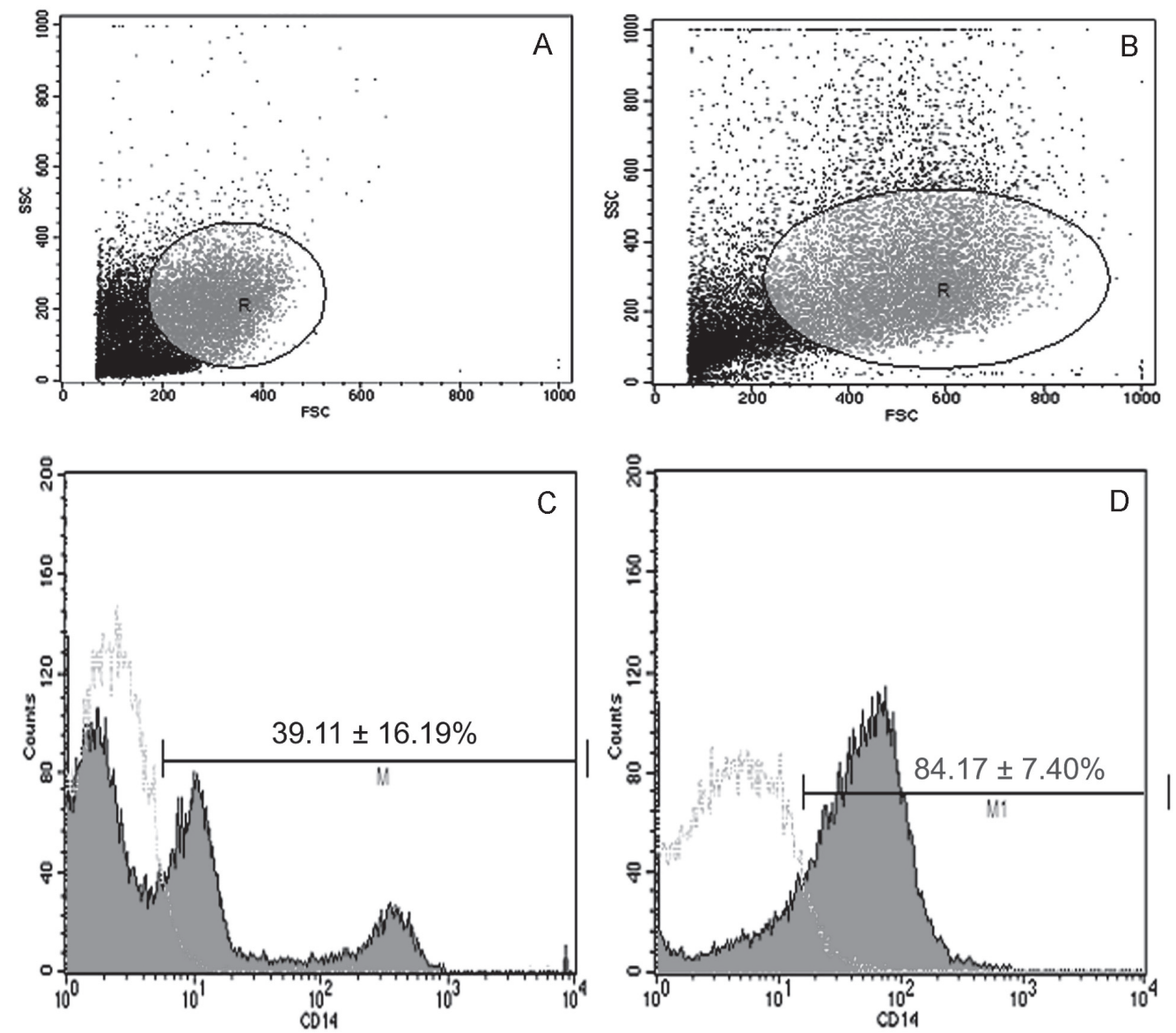

Fig. 2 A/B: representative dot plot of size ( $\mathrm{x}$ axis) vs granularity (y axis) of peripheral blod mononuclear cells (PBMC) immediately after separation in a Ficoll gradient (A) or Teflon-adherent cells cultured for 10 days (B); the selected gates (R) correspond to monocytes in A or monocyte-derived macrophages in B. C and D: representative histograms of CD14 expression in PBMC immediately after separation in a Ficoll gradient (C) or Teflon-adherent cells cultured for 10 days (D). The light gray dot line indicates the distribution of negative controls, and M/M1 indicates the $\mathrm{CD} 14^{+}$population. The values shown in the histogram represen average \pm SD of all analyzed samples. 


\section{REFERENCES}

Dienzle D 2002. Monocytes and macrophages. In BF Feldman, JG Zinkl, NC Jain (eds), OW Schalm's, Veterinary Hematology, 5th ed., Lippincott, Philadelphia, p. 318-325.

Ho CK, Babiuk LA 1979. Long-term culture of canine peripheral blood monocytes in vitro. Can J Comp Med 43: 223228.

Janeway CA, Travers P, Walport M, Shlomchick MJ 2001. Innate immunity. In Immunobiology - The Immune System in Health and Disease, Garland, New York, p. 35-92.

Kurzman ID, Fushun S, MacEwen EG 1993. In vitro and in vivo mononuclear cell production of tumor necrosis factor induced by muramyl peptides and lipopolysaccharides. Vet Immunol Immunopathol 38: 45-56.

Olivier M, Berthon P, Chastang J, Cordier G, Lantier F 2001. Establishment and characterization of ovine blood monocyte-derived cell lines. Vet Immunol Immunopathol 82: 139151.

Panaro MA, Fasanela A, Lisi S, Mitolo V, Andriola A, Brandonisio O 1998. Evaluation of nitric oxide production by Leishmania infantum-infected dog macrophages. Immunopharmacol Immunotoxicol 20: 147-158.

Pinelli E, Gebhard D, Mommaas AM, Hoeij M, Langermans JAM, Ruitenberg EJ, Rutten VPMG 2000. Infection of a canine macrophage cell line with Leishmania infantum: determination of nitric oxide production and anti-leishmanial activity. Vet Parasitol 92: 181-189.

Pinelli E, Rutten VPMG, Bruysters M, Moore PF, Ruitenberg EJ 1999. Compensation for decreased expression of B7 molecules on Leishmani infantum-infected canine macrophages results in restoration of parasite-specific T-cell proliferation and gamma interferon production. Infect Immun 67: 237-243.

Saldarriaga OA, Velásquez JI, Ossa JE, Rugeles MT 2003. Standardization of bovine macrophage monolayers and isolation and culture of trypanosomes. Mem Inst Oswaldo Cruz. 98: 269-271.

Shaw SE, Anderson NV 1984. Isolation and functional analysis of normal canine blood monocytes and resident alveolar macrophages. Am J Vet Res 45: 87-90.

Sisto M, Brandonisio O, Panaro MA 2001. Inducible nitric oxide synthase expression in Leishmania-infected dog macrophages. Comp Immunol Microbiol Infect Dis 24: 247254.

Siqueira AL 2002. Métodos não-paramétricos na análise estatística. In JF Soares, AL Siqueira (eds), Introdução à Estatística Médica, Coopmed, Belo Horizonte, p. 127-165.

Souza PE, Rocha MO, Rocha-Vieira E, Menezes CA, Chaves AC, Gollob KJ, Dutra WO 2004. Monocytes from patients with indeterminate and cardiac forms of Chagas' disease display distinct phenotypic and functional characteristics associated with morbidity. Infect Immun 72: 5283-91.

Tipold A, Zurbriggen A, Moore P, Schijns V, Jungi TW 1998. Generation and functional characterization of canine bone marrow-derived macrophages. Res Vet Sci 64: 125-132.

Wardley RC, Lawman MJ, Hamilton F 1980. The establishment of continuous macrophage cell lines from peripheral blood monocytes. Immunology 39: 67-73. 